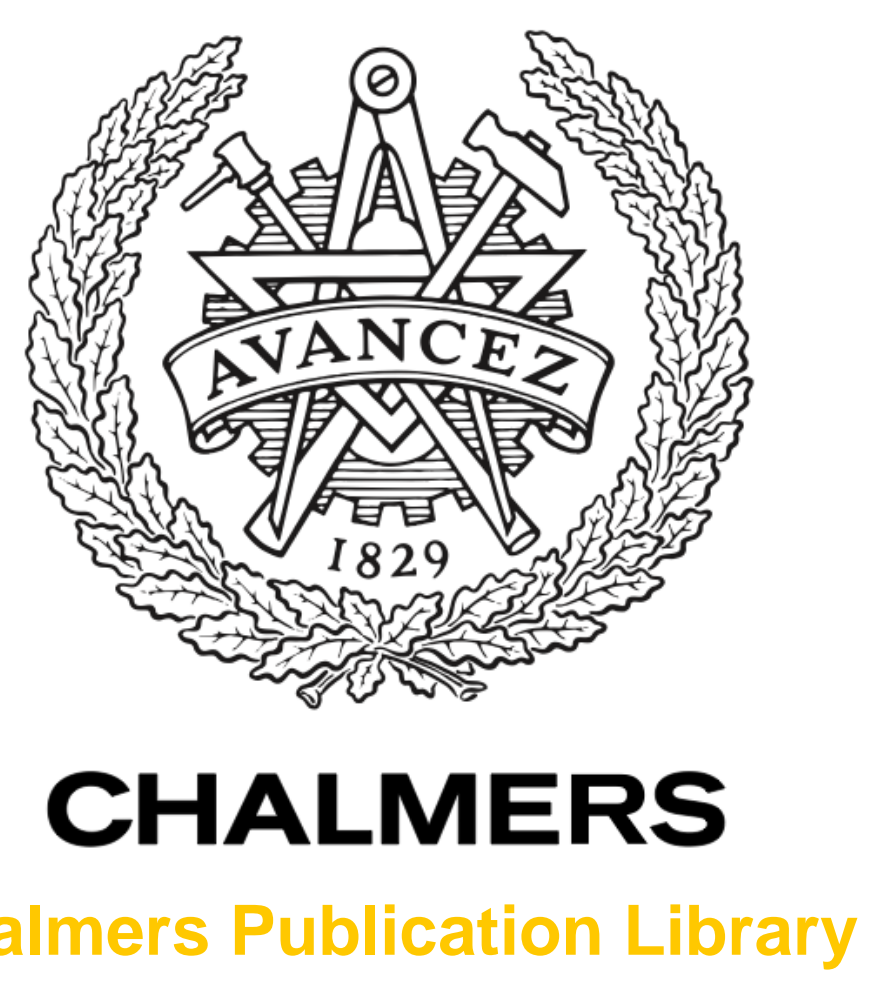

Chalmers Publication Library

\title{
The value of flexibility for pulp mills investing in energy efficiency and future biorefinery concepts
}

This document has been downloaded from Chalmers Publication Library (CPL). It is the author's version of a work that was accepted for publication in:

International Journal of Energy Research (ISSN: 0363-907X)

Citation for the published paper:

Svensson, E. ; Berntsson, T. ; Strömberg, A. (2014) "The value of flexibility for pulp mills investing in energy efficiency and future biorefinery concepts". International Journal of

Energy Research

Downloaded from: http://publications.lib.chalmers.se/publication/197041

Notice: Changes introduced as a result of publishing processes such as copy-editing and formatting may not be reflected in this document. For a definitive version of this work, please refer to the published source. Please note that access to the published version might require a subscription. 


\title{
The value of flexibility for pulp mills investing in energy efficiency and future biorefinery concepts
}

\author{
Elin Svensson ${ }^{1 *}$, Thore Berntsson ${ }^{1}$, Ann-Brith Strömberg ${ }^{2}$ \\ ${ }^{1}$ Heat and Power Technology, Department of Energy and Environment, Chalmers University of \\ Technology, SE-412 96 Göteborg, Sweden \\ ${ }^{2}$ Department of Mathematical Sciences, Chalmers University of Technology and University of \\ Gothenburg, SE-412 96 Göteborg, Sweden \\ "Corresponding author: Tel.: +4631772 3016; Fax: +4631821928. \\ E-mail address: elin.svensson@chalmers.se
}

\begin{abstract}
Changing conditions in biomass and energy markets require the pulp and paper industry to improve energy efficiency and find new opportunities in biorefinery implementation. Considering the expected changes in the pulp mill environment and the variety of potential technology pathways, flexibility should be a strong advantage for pulp mills. In this context, flexibility is defined as the ability of the pulp mill to respond to changing conditions. The aim of this article is to show the potential value of flexibility in the planning of pulp mill energy and biorefinery projects and to demonstrate how this value can be incorporated into models for optimal strategic planning of such investments. The paper discusses the requirements on the optimization models in order to adequately capture the value of flexibility. It is suggested that key elements of the optimization model are multiple points in time where investment decisions can be made as well as multiple scenarios representing possible energy price changes over time. The use of a systematic optimization methodology that incorporates these model features is illustrated by a case study, which includes opportunities for district heating cooperation as well as for lignin extraction and valorization. A quantitative valuation of flexibility is provided for this case study. The study also demonstrates how optimal investment decisions for a pulp mill today are influenced by expected future changes in the markets for energy and bio-products.
\end{abstract}

Keywords: Energy efficiency, forest biorefinery, process integration, investment under uncertainty, multistage stochastic programming, energy price scenarios

\section{Nomenclature}

$\begin{array}{ll}\text { ANP } & \text { Annual Net Profit } \\ \text { CCS } & \mathrm{CO}_{2} \text { Capture and Storage } \\ \text { EMS } & \text { Energy Market Scenarios } \\ \text { ENPAC } & \text { ENergy Price And Carbon balance scenario tool } \\ \text { HEN } & \text { Heat Exchanger Network } \\ \text { MSP } & \text { Multistage Stochastic Programming } \\ \text { NPV } & \text { Net Present Value }\end{array}$

\section{Introduction}

Pulp and paper mills operate in a changing environment in which long-term changes are expected in energy market conditions, political regulations and technological development. The energy-intensive pulp and paper industry is clearly under pressure to respond to these changes. However, owing to forest companies' control and experience of renewable biomass resources, their opportunities 
connected to these changes are numerous. These opportunities include traditional products such as green electricity, wood fuels, and district heating. The export of these energy products can be increased by investing in new, more efficient back-pressure turbines, or in low-pressure, condensing turbines, by saving steam and reducing the load in existing biomass boilers or by using excess heat from the mill in a better way. Maybe more importantly, the opportunities also include emerging biorefinery concepts with the production of green transportation fuels, new specialty chemicals and biomaterials (see e.g. [1, 2]). These products require investments in technologies and processes that are new to the pulping industry. Some examples of these technologies and processes are the gasification of black liquor or woody biomass and processes for the extraction of hemicellulose from wood chips or lignin from black liquor.

Considering the changes expected in the pulp mill environment and the variety of potential technology pathways, flexibility, which in this article is defined as the ability of the pulp mill to adapt to changing conditions, will become a strong advantage for the pulp mill companies.

A requirement for the successful implementation of energy and biorefinery retrofit projects in existing pulp and paper mills is that the resulting processes use energy and material in an efficient way. The focus of this article is on the energy system of a pulp mill and the optimization of pulp mill investments. The investments considered are traditional measures for improved overall energy efficiency and the energy efficient implementation of an integrated biorefinery concept based on lignin extraction. A higher overall efficiency of a process plant can be achieved by a better combination of unit processes, that is, through process integration. Methods for process integration include a wide variety of tools for heat as well as material integration (see, e.g., Kemp [3], Smith [4] and Klemeš [5]). The use of process integration in the pulp and paper industry has been covered in an excellent review paper by Atkins et al. [6]. The heat savings considered in the paper at hand are achieved through heat integration as well as through investments in more efficient equipment and process units.

The optimal decisions for investments in process energy projects depend on the development of energy prices over the lifetime of the investments. Assuming that prices will remain constant at their current levels is unrealistic. As shown by Nemet et al. [7], models for the optimization of investments in heat recovery should therefore include the future development of energy prices. Nemet et al. [7] have created a multi-period model for Heat Exchanger Network (HEN) synthesis that takes into account future projections of utility prices over the lifetime of the HEN. They show in a case study that the design obtained with their multi-period model resulted in hot utility savings of $18.4 \%$ and an increase in the Net Present Value (NPV) by $7.8 \%$ compared to the design obtained using fixed current prices. This finding demonstrates the importance of considering expected future projections of energy prices over the entire lifetime of an investment. Since the models proposed by Nemet et al. [7] have been developed specifically for HEN synthesis they are, however, not directly applicable for investments in more general energy savings and biorefinery processes in the retrofit of an existing pulp mill.

\subsection{Literature review}

Studies of the optimal strategic choice between larger packages of energy efficiency and biorefinery investments, such as the ones used in this article, include [8-10]. Ådahl and Harvey [8] have proposed a methodology for evaluating process industry energy investments that considers different scenarios for the long-term development of future climate policy regulations. These scenarios represent paths of changing energy prices over time. Tay et al. [9] have proposed an approach to the optimal retrofit of an existing pulp and paper mill into an integrated biorefinery. Their work considers the long-term 
change and uncertainty in the supply and demand of biomass products rather than in the prices of energy and biorefinery products. Furthermore, their method does not explicitly include the heat integration of the integrated biorefinery in the optimization model. Liu et al. [10] have proposed an optimization approach for designing a polygeneration energy system assuming normally distributed uncertainties in energy prices and demands, however, not considering variations in the long-term trends of these parameters.

The studies [7-10] have considered investment opportunities at the start of the planning period only. The flexibility obtained by enabling investments at later points in time - so-called recourse decisions as reactions to changing conditions was consequently not considered. However, not only energy prices, but also investment costs, especially for emerging technologies, are expected to change over time. Consequently, the profitability of an investment also depends on the timing of the investment. Within the economic field, the importance of investment timing is acknowledged and described by the real options theory (see e.g. [11]). In equivalence with the study presented here, the objective of a real options problem is to maximize an expected value, and subsequently both the choice of investments and their timings are optimized. The optimization problem considered in the article at hand essentially represents a real options investment problem. As such, the option values of all alternative investments, including the option value of waiting, are simultaneously considered. The real options approaches include the methods most commonly used to calculate the value of real options and to solve the real options investment problem, as for example, dynamic programming and contingent claims analysis (see e.g. [11, Ch. 4]). Multistage Stochastic Programming (MSP) (see e.g. [12-14]), which is used here, is not typically one of those methods. However, the MSP approach has been chosen for this study because of the requirements on process modelling (see Section 2). Hence, we claim that the methodology applied in this article is chosen based on assumptions that fit into the real options theory, although the method is not strictly a real options approach.

Several studies (e.g. [15-19]) apply the real options approach to investments in power generation in the energy sector. They typically investigate how climate policy uncertainty, sometimes combined with energy market uncertainty, affects the investment behaviour of private companies and they all confirm the importance of accounting for uncertainty and timing. A few studies employing the real options approach have been applied to the industrial sector and investments in heat production and energy efficiency (e.g. [20-22]). Wickart and Madlener [20] have developed a model for choosing between a combined heat and power production and a heat-only production for an industrial firm. The model determines the best technology choice as well as the timing of the investment. The study of investments in energy saving technology for greenhouses in the horticultural sector [21] is another example using the real options methodology. The real options approach has been applied in the pulp and paper industry by Chladná et al. [22], who investigated the expected optimal timing for investment in $\mathrm{CO}_{2}$ capture under uncertainty. Since the steam demand of the pulping process is assumed to be fixed, no process integration opportunities are considered, and only three distinct process configurations are modelled. The model thus allows for the optimization of the investment in $\mathrm{CO}_{2}$ capture, but considers no competing technologies. While the study by Chladná et al. [22] considers a few, discrete process configurations, the most common real options approaches are typically not applicable when a more detailed process modelling is desired. This is the case when considering investments in process integration and several competing technologies for which the capacities are not predefined. Such investment decision problems include not only the optimization of discrete investment decision variables, but also the optimization of continuous process variables, such as equipment size and heat flows that are related through heat balances and capacity constraints. To the 
authors' knowledge, the real options approach has so far not been used to solve process integration investment problems. This can most likely be explained by the inherent lack of ability of most common real options approaches to model process interactions between different investment options in sufficient detail. It should be mentioned, however, that Sharma et al. [23] have suggested the inclusion of a module for real options evaluation in their framework for decision analysis regarding the design of biorefineries, including process integration considerations. In that study, the real options module is suggested to account for uncertainties with respect to product demands and prices and is intended to enable decisions in smaller steps as reactions to changing conditions. Nevertheless, the model presented in [23] assumes constant fuel and electricity prices; the real options module has yet to be implemented.

A methodology for the optimization of process energy investments under uncertainty has been developed by Svensson et al. [24-25]. The methodology considers both the future development of the price of energy and investment costs, and the multiple investment opportunities over time. However, these aspects of the modelling have not been analyzed and discussed; the focus has been on the modelling and effect of uncertainty only.

Few models for process energy and biorefinery investments capture the change over time of external conditions and very few models include investment opportunities at more than one point in time. Therefore, most such models do not capture the value of the flexibility required to react to changing conditions. Consequently, the significance of change, flexibility, and multiple investment points needs to be illustrated and examples of quantitative levels of these effects need to be provided. This is the contribution of study reported in this article.

\subsection{Aim}

The aim of this article is to reveal the potential value of flexibility when planning pulp mill energy and biorefinery projects. An example illustrates how the optimal investment decision for a pulp mill today is influenced by expected future changes in the market for energy and bio-products.

The aim includes demonstrating how this flexibility value can be incorporated into methodologies for the strategic planning of such investments. The article discusses the key elements required in the optimization models in order to adequately capture the value of flexibility.

\subsection{Scope}

This article considers the strategic planning of energy and biorefinery investments at a pulp mill. The overall strategy of the firm, for example, the long-term planning of a mill's existence, the pulp product quality and the production rate, is assumed to be fixed. Furthermore, changes in the markets for energy, biorefinery products and biomass feedstock, and the development of policy instrument levels are considered exogenous, that is, beyond the control of the pulp mill managers. As a response to these external changes, the pulp mill needs to identify a strategic investment plan for energy efficiency improvements and biorefinery implementation.

\section{Methodology}

In this article we use an optimization-based methodology to study the value of flexibility to certain as well as uncertain changes in the surrounding conditions. A summary of the modelling framework used is presented in Section 2.1. This section also describes the methodology for modelling of uncertain and changing energy prices. Section 2.2 describes the methodology for how these models and tools are used to evaluate flexibility in this study. 


\subsection{Modelling framework}

Multistage Stochastic Programming (MSP) (see e.g. [12-14]) is a suitable approach for considering uncertainty when optimizing investment decisions for complex systems. A previously developed MSP-based methodology [24] and optimization model [25] has therefore been used in this study. This section presents an overview of the modelling assumptions, the different components of the model, including variables, objective function and constraints, and the model properties. A detailed description of the optimization model formulation is presented in [25].

The goal of the MSP modelling is to identify a set of investment decisions that maximize the expected NPV. The optimization model includes some parts that need to be defined for each specific case study. These include the investment options to be considered and the parameters describing their characteristics. For each case study, the constraints describing how different energy efficiency measures can be combined must also be defined. The case specific model components also include the definition of relevant energy market scenarios. In addition, the optimization model includes generic components representing the objective function, mass and energy balances and energy conversion.

\section{Decision variables, technology and cost parameters}

The investment decision variables belong to one of two sets, which are labelled as heat-saving measures and energy-conversion technologies respectively. The heat-saving measures are defined as investments or investment packages that result in a fixed amount of heat (typically steam) saved at a certain cost. These heat-saving measures can either be investments in heat recovery identified using pinch analysis (see e.g. [3-5]), or investments in new, more efficient unit processes. For the energyconversion technologies, the capacity is optimized by the model and the investment cost is given as a function of the capacity. The output of an energy-conversion technology is a product such as electricity, dried bark, district heating, biofuel or some kind of biobased material or chemicals for which the product output is a function of the steam flow allocated for that technology. These energyconversion technologies offer the potential to generate an income from heat savings, either by increasing the export of energy and biorefinery products or by reducing the import of external fuel.

A number of parameter values must be defined in the optimization model for the energy savings and for the energy-conversion technologies. The required input data include investment costs and steam savings for the energy-saving measures, and energy conversion data and investment cost functions for the energy-conversion and biorefinery technologies.

The modelling of investment and operating decisions in relation to the energy market development has been based on a few fundamental assumptions that follow the theory of MSP. It has been assumed that investment decisions are made 'here-and-now', which means that they are decided on and implemented before uncertainties in energy prices are resolved and any change of prices occur. After the uncertainties have been resolved, new 'here-and-now' decisions about additional investments can be made, before any further price changes occur. The operating decisions for the plant are also determined by the model. Depending on the investments made, for example, the production of electricity or the use of fuel may be adjusted.

\section{Constraints}

The investment and operating decisions are limited by a number of constraints and requirements. Some of these constraints are general and valid for most investments in industrial energy systems, while others depend on the mill characteristics and therefore must be formulated with respect to prevailing conditions. 
The main constraints of the model are formulated as mathematical equations and inequalities and describe the relations between investment decisions and costs, energy savings, and overall mass and energy balances. Other, logical, constraints typically define how heat-saving measures can be combined, and how they influence each other. These constraints are specifically formulated in the model for each case study. Examples of basic constraints are that two measures cannot be combined or that the implementation of one measure requires the implementation of another one. More complex constraints often arise due to non-linear relations when the effect of combining two or more process retrofit measures is not purely additive. Since the model must be linear, such non-linear relations need to be reformulated, which typically requires several linear constraints and additional, binary variables.

\section{Objective function and optimal solution}

The objective of the optimization model is to find the combination of investments that results in the highest expected NPV over all Energy Market Scenarios (EMS) considered. The objective function is expressed as to

$$
\operatorname{maximize} \mathrm{E}[\mathrm{NPV}]:=-C_{0}+\sum_{s \in S} p_{s} \sum_{t=1}^{T} \frac{C_{t, s}}{(1+r)^{t}}
$$

where

$$
\begin{aligned}
& C_{0}=\text { the initial investment cost } \\
& S=\text { the set of all EMS } s \\
& p_{s}=\text { the probability of scenario } s \text { to occur, } \\
& T=\text { the lifetime of investments, } \\
& C_{t, s}=\text { the net cash flow in year } t \text { for scenario } s, \text { and } \\
& r \quad=\text { the discount rate. }
\end{aligned}
$$

Since the first investment decision is made before the values of future energy prices are known, equal initial investments are required for all the EMS considered. The yearly net cash flow is a function of the operating decisions and the prices of energy for that year, but it can also include costs for new investments. The operating decisions concern, for example, the amount of electricity generated in a turbine or the amount of heat delivered to a district heating network. These operating decisions are constrained by the capacity in technology available from earlier investments and by mass and steam balances. The net cash flow of the final year, $C_{T}$, should be adjusted for the residual value of the investments (see [25, Appendix A], for details and assumptions).

The optimal solution thus contains information about which investments to make at the present time and at later points in time in the different scenarios. The optimal capacity of energy-conversion technologies is also determined, as well as operational decisions for each time period and scenario. Based on the investments made, the operational decisions, and the energy prices set by the EMS, the cash flows for all scenarios and time periods are also calculated.

\section{Scenario model for energy market parameters}

Energy prices are considered uncertain in the model and are therefore modelled by a scenario-based approach. The selection of energy-conversion technologies to include in the model determines the products for which prices are required.

To calculate the expected value in (1), a probability distribution for the possible outcomes of uncertain parameters is required. On a long-term time scale, the uncertain energy market parameters are assumed to not only vary according to historical trends. They are also assumed to change owing to future developments following strategic climate policy decisions and/or changes in the reliability of 
fossil fuel supply. The probability distribution is therefore not straightforwardly based on historical data, statistics or probability theory. Instead, a probability distribution can be assumed to represent the decision-makers' beliefs about the future development of the energy market. This is done by letting the probabilities of a finite number of plausible outcomes (scenarios) be defined by relative weights based on experience and/or preference (see e.g. [26]).

Here, the EMS represent different developments in the prices of energy and in energy market policy instruments. The model captures the correlation between parameters by letting each node in the scenario tree represent a consistent set of parameter values, allowing only realistic combinations of electricity and fuel price levels. To construct consistent sets of energy market parameters, a calculation tool called ENPAC (Energy Price and Carbon Balance Scenarios tool) has been used [27]. This tool was developed for the evaluation of energy-efficiency investments in energy-intensive process industry. Based on user input about world market fossil fuel price data and assumed values for energy and climate mitigation policy instruments, the scenario tool calculates electricity and fuel prices for large-volume customers based on pre-defined characteristics of a number of energy-conversion technologies. These technologies are potential candidates for marginal electricity production and marginal wood fuel use (see Figure 1).

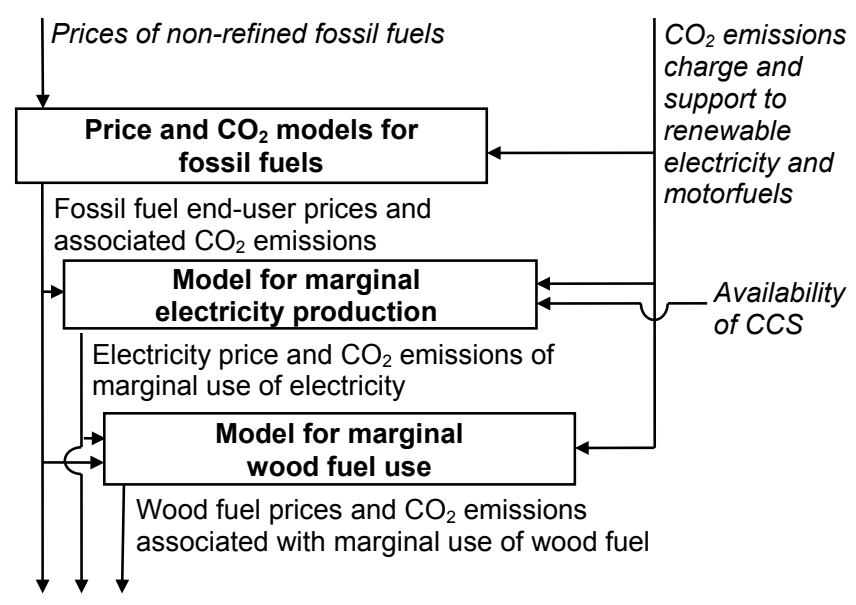

Figure 1. Overview of the ENPAC calculation tool [27] for generation of consistent energy market parameter sets. The input (fossil fuel prices and levels of policy instruments) is set by the user. The output (prices and $\mathrm{CO}_{2}$ emissions associated with fossil fuels, wood fuels and electricity) forms the basis for scenario data in the investment optimization model.

The case study presented in this article use energy market data based on ENPAC [27], as described in Section 3.2.

\section{Model properties - integer variables and linear functions}

The final optimization model is a mixed-binary linear, multistage stochastic programming model. It should be noted that non-linearity can be avoided in the model despite the presence of recourse stages, owing to the formulation of a discrete probability distribution. In this project, the final mixed-integer linear programming model is implemented in AMPL [28] and solved using the optimization solver CPLEX [29]. 


\subsection{Evaluation of flexibility}

In this paper, the optimization framework described above has been used to evaluate the value of flexibility for a mill that is faced with a potential future biorefinery opportunity. The analysis is completed by solving the model for the following cases:

Reference case: A model in which the future biorefinery opportunity is not considered

Main cases: A model including a future biorefinery opportunity with

(A) no explicit limitations in flexibility,

(B) a reduced flexibility, through the addition of constraints limiting the possibilities, for example, for later investments or adjustment of operations as a response to changing conditions

In order to determine the value and evaluate the effect of flexibility when considering future changes, the optimal solutions and objective values of the model cases (A) and (B) are compared. The value of flexibility can then be calculated, for example, as the difference of the expected NPV between the cases (A) and (B). This value, however, represents an expected loss of flexibility over a range of scenarios and time periods. In order to better assess the economic loss when flexibility is reduced, the cash flows given by the optimal solutions can be used to calculate the annual net profits (ANP) for each scenario and time period individually. Hence, the time and scenario specific value of flexibility is calculated as

$$
\begin{aligned}
\Delta \mathrm{ANP}_{t, s} & :=\mathrm{ANP}_{t, s}(\mathrm{~A})-\mathrm{ANP}_{t, s}(\mathrm{~B}) \\
& =\left[C_{t, s}^{\mathrm{op}}(\mathrm{A})-a \sum_{i=0}^{t-1} C_{i, s}^{\mathrm{inv}}(\mathrm{A})\right]-\left[C_{t, s}^{\mathrm{op}}(\mathrm{B})-a \sum_{i=0}^{t-1} C_{i, s}^{\mathrm{inv}}(\mathrm{B})\right]
\end{aligned}
$$

where

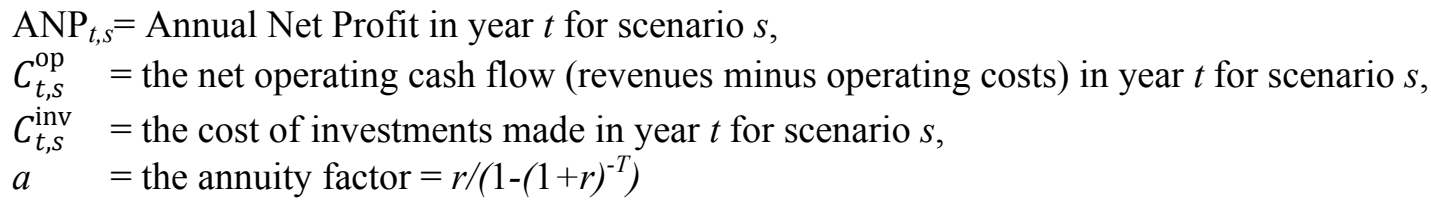

\section{Case study}

\subsection{Mill description}

The studied pulp mill has previously been analyzed with respect to energy-saving opportunities in its hot and warm water system [30]. That study also considered the influence of process variations on the energy-saving potential and the optimal HEN configuration. The mill is modelled to produce 425,000 ADt (air-dried tonnes) of bleached Kraft pulp per year from both hardwood and softwood. The mill is sited nearby a district heating network. The current combined steam consumption for the process and the district heating deliveries is $230 \mathrm{MW}$. The total steam production in the recovery and bark boilers at the mill is $272 \mathrm{MW}$. Since the burning of black liquor and bark covers the energy demand of the process the mill is not assumed to import any additional fuel. 


\subsubsection{Potential for steam savings and excess heat}

The potential increase in annual average delivery of heat from the mill to the district heating network is estimated to $13.8 \mathrm{MW}$ [31]. This can be covered with excess heat from the pulping process. However, the excess heat could, alternatively, be used in the evaporation plant to save steam (see Table 1) or in a process for the conversion of lignin into a higher-valued product (see Section 3.1.3). The steam-saving measures available in the mill are modelled as discrete options of fixed investment costs resulting in a certain amount of heat savings (see Table 1).

Table 1. Steam-saving measures. Data from [30] together with estimations from [32-33].

\begin{tabular}{lcc}
\hline Steam-saving measure & $\begin{array}{c}\text { Steam } \\
\text { saving } \\
{[\mathbf{M W ]}}\end{array}$ & $\begin{array}{c}\text { Investment } \\
\text { cost } \\
{[\mathbf{M} \boldsymbol{C}]}\end{array}$ \\
\hline 1. Heat recovery in the hot and warm water system & 13.3 & 1.2 \\
2. Modernized conventional evaporation plant & 20 & 15 \\
3. Modernized evaporation plant using excess heat & 32 & $20 / 10^{\text {a }}$ \\
4. Utilization of heat from flue gases to replace steam & 6 & 1 \\
\hline${ }^{\mathrm{a}}$ If an investment has already been made in a conventional plant, the cost for further \\
upgrading to use excess heat is assumed to be 10M€.
\end{tabular}

\subsubsection{Opportunities for adjusting the energy balance in response to a reduction in steam demand}

Process heat savings provide the opportunity to increase the export of district heating or electricity from low-pressure steam or to reduce the steam production at the mill. However, reducing the steam production also causes a decrease of the electricity production in the back-pressure turbine. Figure 2 shows a simplified illustration of the energy system at the pulp mill. 


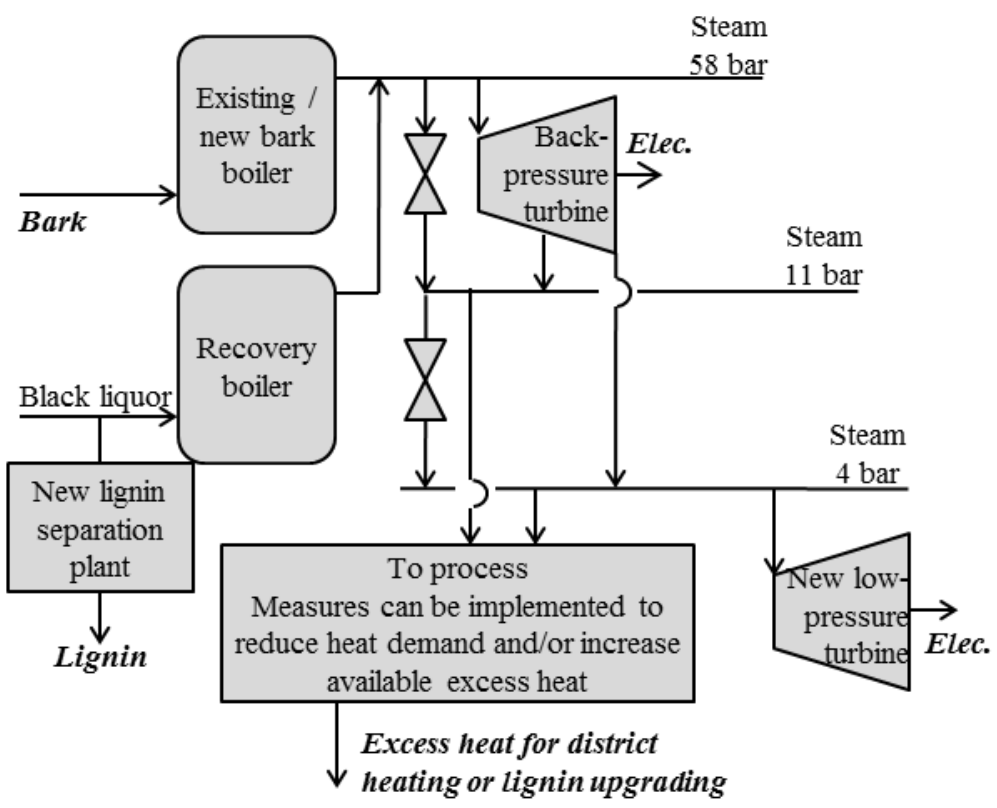

Figure 2. A simplified picture of the model of the pulp mill heat production and distribution system, and of the opportunities for energy exports used in the case study (see also Table 2).

For the existing bark boiler, it is assumed that the current average load is required to be maintained in order to ensure operational flexibility in relation to the large seasonal load variations in district heating demand ${ }^{1}$. Decreasing the load of the recovery boiler, on the other hand, can only be accomplished by separating lignin from the black liquor. If the value of lignin is significantly higher than that of bark, high lignin extraction rates can be interesting even if the steam demand has not been sufficiently decreased to allow for a large reduction in steam production. In order not to jeopardize the operation of the recovery boiler, the maximum lignin extraction rate has been set to a value corresponding to about $10 \%$ of the total dry solids flow of the black liquor (see [34]). The model also includes the option of investing in a new bark boiler for higher steam production from bark or purchased wood fuel. A new bark boiler will enable compensation for lignin extraction rates that reduce the steam production in the recovery boiler by a greater amount than what is allowed for by the steam savings.

\subsubsection{Opportunity for further processing of lignin}

Extracted lignin is currently valued as a wood fuel, but in the future it is possible that lignin may be further processed at the mill into products that can be valued as material or chemicals. A further refining of lignin would require an investment in a new conversion process which, optimally, should be integrated with the existing pulping process. Since data for lignin refining processes are scarce, this part has not been modeled in detail. Instead, it has been assumed that if a new process for the valorization of lignin becomes available, the price for lignin will be set in relation to oil rather than

\footnotetext{
${ }^{1}$ Further work is needed, however, to model the seasonal variations more explicitly. These variations might affect the competitiveness of the bark boiler compared to new technology at the mill.
} 
wood residues. Furthermore, a constant term has been added representing, among other factors, the difference between the part of the added value of the new bio-product that is not related to its heat content and the specific cost of the investment made at the mill site (see also Section 3.2.1, 'Lignin price'). To illustrate the integration aspects, the new process was assumed to have a heat demand at about $80^{\circ} \mathrm{C}$, which can be covered with excess heat from the pulping process. However, if excess heat is used for district heating or in the evaporation plant, the heat demand of a new lignin upgrading process must instead be covered with steam.

To summarize, the lignin upgrading process is included as an energy-conversion process that use extracted lignin and heat as input to produce lignin of a higher added-value. The heat can be either low-temperature heat or low-pressure steam. No investment cost is set for the lignin upgrading process. The investment is instead included as an annualized cost in the final lignin price.

\subsubsection{Summary of the energy-conversion technologies included in the model}

The energy-conversion technologies included in the model are listed in Table 2, including brief characterizations and investment cost functions. For more details on the pulp mill energy system and the data for the energy-conversion technologies the reader is referred to the previous studies [30-33].

Table 2. Energy-conversion technologies included in the case study. Data from [31,32].

\begin{tabular}{lc}
\hline Energy-conversion technologies & $\begin{array}{c}\text { Investment cost } \\
\text { [M€] }\end{array}$ \\
\hline $\begin{array}{c}\text { Existing back-pressure turbine (currently operated at full capacity) } \\
\text { isentropic efficiency }=0.85\end{array}$ & 0 \\
$\begin{array}{l}\text { Lignin extraction } \\
\text { Low-pressure condensing turbine } \\
\quad \text { isentropic efficiency }=0.81\end{array}$ & $1.02 Q^{0.6}$ \\
$\begin{array}{l}\text { New bark boiler } \\
\text { District heating from low temperature excess heat } \\
\quad \text { incl. new pipeline }\end{array}$ & $2.38 Q^{0.6}$ \\
\hline$Q:$ output capacity $[\mathrm{MW}]$ & $1.64 Q^{0.76}$ \\
\hline
\end{tabular}

\subsection{Scenario model used in the case study}

Basic input data for the scenario model were provided to the scenario tool ENPAC [27] for this study and include different levels of charges for $\mathrm{CO}_{2}$ emissions and of fossil fuel prices. The input data to ENPAC were based on the original data used for the example scenarios in the ENPAC report [27]. However, a number of adjustments of the original data were made in order to represent scenarios of higher probability and to obtain multiple branching nodes in the scenario tree (see [35] for details). Figure 3 shows the adjusted input to the scenario tool for the crude oil price and the charge for $\mathrm{CO}_{2}$. The main assumptions on the remaining input data to the scenario tool are listed below.

- The support for electricity production from wood fuel is constant at $€ 20 / \mathrm{MWh}_{\mathrm{el}}$ according to the original input.

- $\mathrm{CCS}\left(\mathrm{CO}_{2}\right.$ Capture and Storage) is assumed to be available for the price-setting electricity production technology at the earliest in five years after becoming the most cost-effective alternative for electricity production.

- The support for production of renewable transportation fuel is, in accordance with the original input, set to represent a harmonization of the $\mathrm{CO}_{2}$ emission trading scheme over all sectors, including the transportation sector. The result of this setting is that for a majority of the scenarios, the marginal use of wood fuel is to co-fire it in coal power plants. 

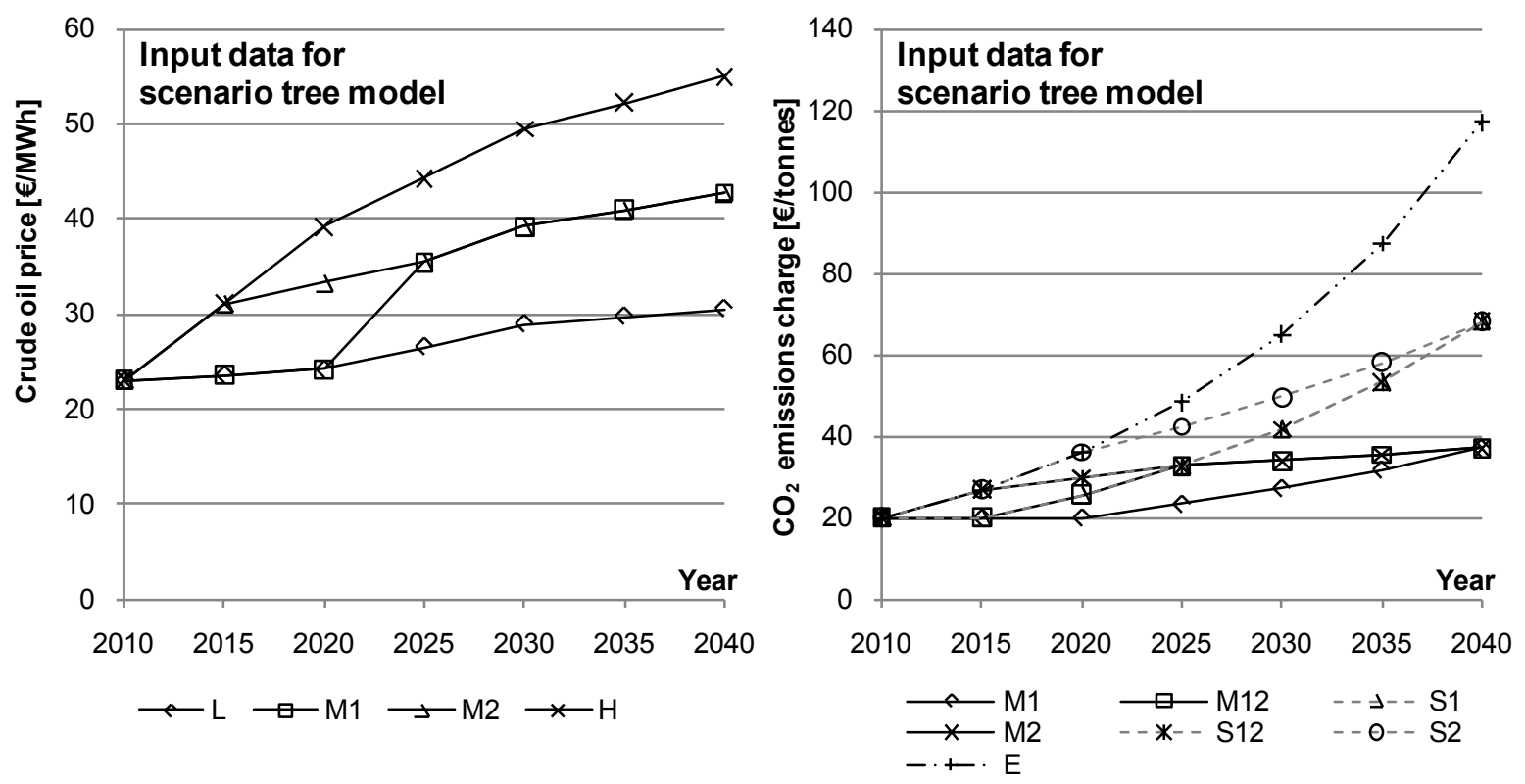

Figure 3. Data set as input to the ENPAC tool to construct scenario data for the MSP model. One data point from each of the left and right figures form the input for one energy market parameter set, that is, one node in the scenario tree. Left: Fossil fuel prices exemplified by the price of crude oil (L: Low price increase, M1/2: Moderate price increase, $\mathrm{H}$ : High price increase). Right: Charge for $\mathrm{CO}_{2}$ emissions, i.e., the price of $\mathrm{CO}_{2}$ emission permits (M1/12/2: Moderate $\mathrm{CO}_{2}$ charge increase, S1/12/2: more "Sustainable" $\mathrm{CO}_{2}$ charge increase, E: "Extreme" $\mathrm{CO}_{2}$ charge increase). The difference between scenarios $1 / 12 / 2$ is the timing of the most emphasized price increase. Data from [35].

By combining each of the seven $\mathrm{CO}_{2}$ charge scenarios with each of the four fossil fuel price scenarios, the resulting 28 scenarios (120 nodes) in the scenario tree were obtained (see Figure 4). Electricity and fuel prices for industrial customers were calculated for each node using the ENPAC tool and applying the above assumptions. The resulting prices of electricity and bark given as output from the tool are presented in Appendix A. The range of values for the electricity price is illustrated in Figure 5. The prices of electricity and bark are used as input to the optimization model. 


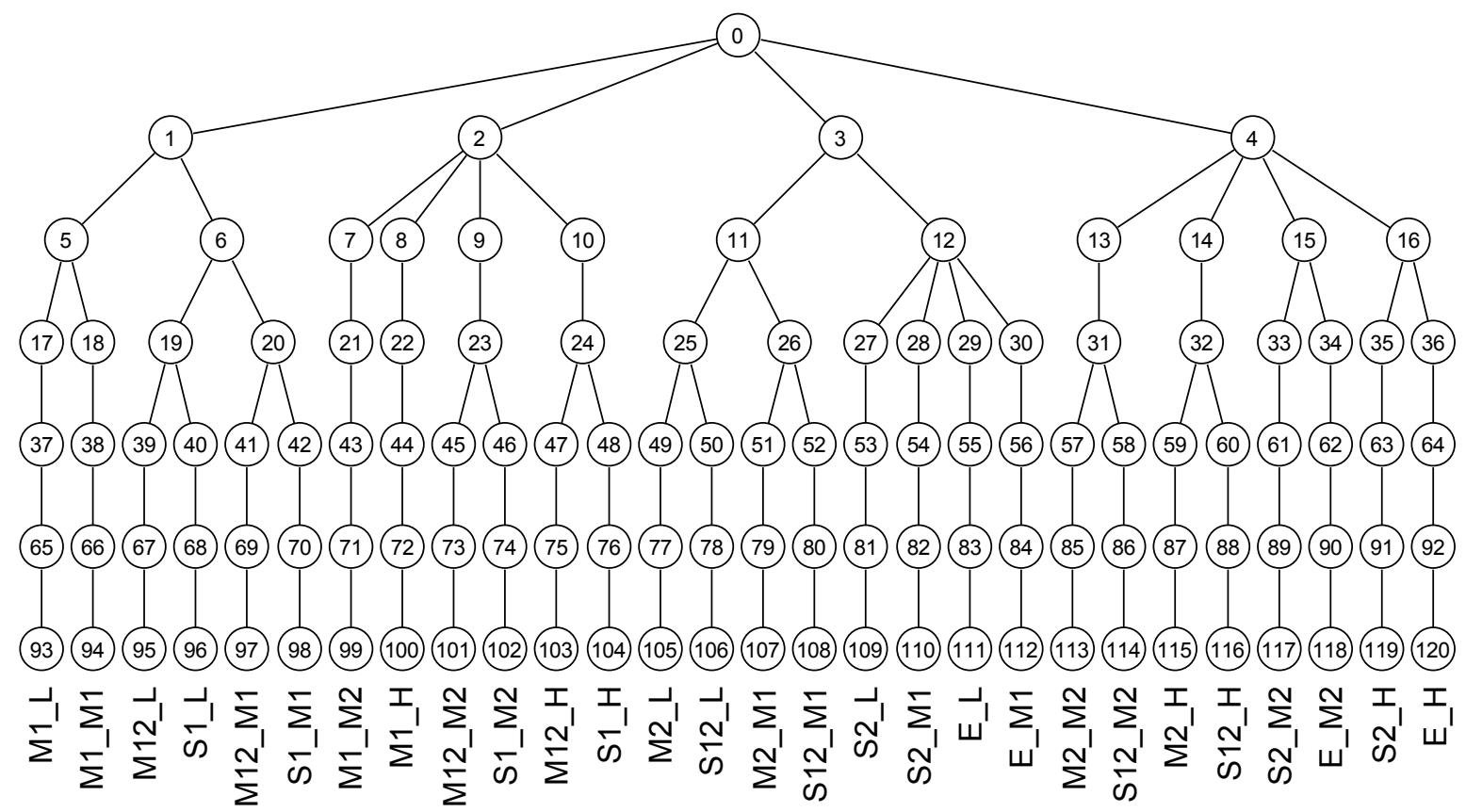

Figure 4. A scenario tree consisting of 120 nodes (28 scenarios). The scenarios are labelled according to their construction from input data ([COO $\mathrm{O}_{2}$ charge scenario]_[Fossil fuel price scenario]). Each node represents a consistent set of energy market data as presented in Appendix A.

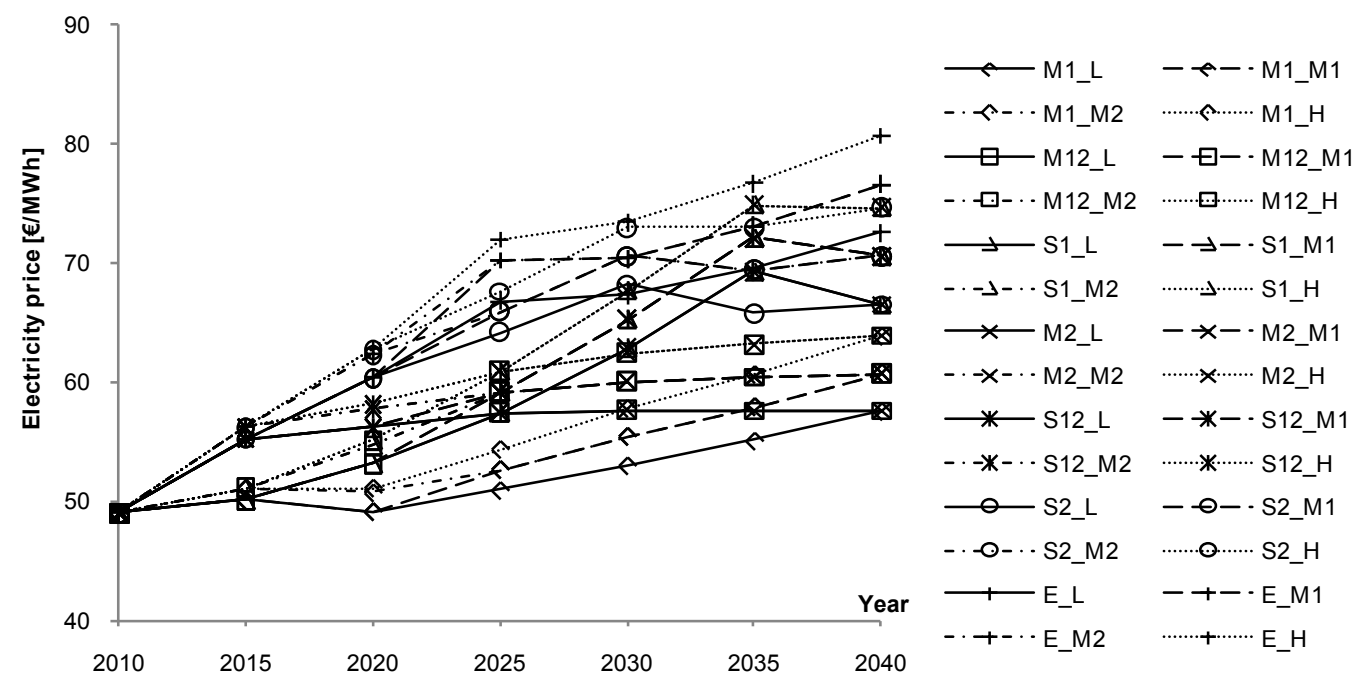

Figure 5. Electricity prices (the value of the green certificates excluded) calculated using the ENPAC tool for a scenario tree of 120 nodes (28 scenarios). Each point represents a combination of input data for fossil fuel prices and $\mathrm{CO}_{2}$ charges as illustrated in Figure 3. Data from [35].

\subsubsection{Assumptions for the construction of additional input to the optimization model from the output of the scenario tool}

Specialty products such as lignin are not included in the scenario tool ENPAC. To obtain prices of such products, complementary assumptions and further calculations have to be made based on the results from ENPAC. Complementary assumptions and calculations are often needed also for district heating since its value is strongly connected to the characteristics of the existing production capacity and the heat demand of the district heating network. 


\section{District heating price}

The price of district heating was set in relation to its alternative production cost. Since the data for the mill in this study were based on typical Swedish mills, assumptions made for the local district heating network were based on Swedish conditions. In Sweden, there is a large share of biomass in the district heating sector. The price of district heating was therefore set to $75 \%$ of the alternative production cost in an existing biofuel boiler, which in turn was calculated from the cost of wood fuel computed by ENPAC.

Lignin price

No market price for lignin has yet been established. Depending on the assumed use of lignin as a highgrade wood fuel or a raw material for chemicals or materials, the value can be set in relation to the wood-fuel price or the oil price, both of which are available from the ENPAC tool.

Different assumptions about the value of lignin were made in different EMS for this case study. The reference price, assumed to be valid in 2010 and with $50 \%$ probability in the future was set to $135 \%$ of the price of low-grade wood fuel such as forest residues (tops and branches) or bark from the pulp mill (as given by the scenario tool). A higher price, representing lignin as a replacement for oil as the feedstock for chemicals production, with 50\% probability after 2015 was set equal to the oil price + $€ 10 / \mathrm{MWh}$. The constant term $10 € / \mathrm{MWh}$, represents the resulting value of the product being renewable, but also takes into account the difference in costs between the lignin- and oil-based processes. This difference can involve factors such as different operating costs and annualized investment costs between the two process routes.

\section{Electricity certificates}

The modelled mill was assumed to be located in Sweden where there is a system of green electricity certificates which are granted to new production plants for a period of 15 years. The value of the green certificates was assumed to be constant at $20 € / \mathrm{MWh}$.

\subsubsection{Scenario probabilities}

Since the focus of this article is not the uncertainty analysis, and for simplicity, the probabilities of all EMS have been assumed to be equal. For actual decision-making it is, however, important to analyze the sensitivity of the solutions with regard to this assumption (see [25] for an example of how this analysis can be performed).

\subsection{Case study results}

\subsubsection{Optimal investments}

The model was first solved for the reference case described in Section 2.2, in which no future biorefinery opportunity is considered and lignin is consequently valued as a wood fuel. The initial investments constituting the optimal solution for each of the EMS considered in the reference case are shown in Table 3. 
Table 3. Optimal initial investments in the reference case: Lignin is valued as wood fuel.

\begin{tabular}{lc}
\hline Investment & Investment cost \\
& {$[\mathbf{M} €]$} \\
\hline Steam savings ${ }^{\mathrm{a}}, 39.3 \mathrm{MW}$ & 17.2 \\
District heating, $13.8 \mathrm{MW}$ & 7.1 \\
Condensing turbine, $7.2 \mathrm{MW}$ & 7.8 \\
\hline
\end{tabular}

${ }^{a}$ corresponding to Measures 1, 2 and 4 in Table 1

The resulting investments involve steam savings and utilization of excess heat and steam for district heating and electricity production, but no lignin extraction. These results are explained by district heating being an attractive option because of favourable district heating prices. The production of district heating can also be straightforwardly combined with a condensing turbine. Lignin extraction is therefore competitive only at very high lignin prices. When lignin is valued as a wood fuel like in this reference case, competitively high lignin prices will occur only in a few EMS and even in those, not within the nearest future.

The model was then solved for Case (A), in which the future possibility to upgrade lignin to a highervalued product at the mill was considered. In order to model this possibility of receiving a higher lignin price in the future, the 28 reference case scenarios were complemented with 28 additional scenarios. These additional scenarios were based on the original ones, but the value of lignin after year 2015 was a function of the price of oil rather than wood fuel. As described in Section 2.2, Case (A) includes no constraints that explicitly limit the flexibility of the mill to adapt to changed conditions. In this case study, this means that there are no constraints on long-term agreement for district heating deliveries. The initial investment in the optimal solution was, however, the same for Case (A) as for the reference case. Nevertheless, in the scenarios with the higher future price of lignin, an investment would be made in lignin extraction at the later point in time when the lignin price is sufficiently high to make lignin export competitive with district heating delivery. At this point district heating delivery would be interrupted. Consequently, these results indicate that a long-term district heating contract should be avoided.

The reference case solution shows that if only low lignin values are achievable, district heating delivery is optimal over a long time period. Based on today's conditions, disregarding the possibility of change in future conditions, the mill could therefore very well consider entering a long-term district heating contract. The results from Case (A), however, illustrates the importance of considering future changes in energy and biorefinery product prices in combination with later investment opportunities.

\subsubsection{Effect of the long-term district heating contract}

The results from Case (A) demonstrate how a long-term contract may be unfavourable if lignin is valued higher in the future. To evaluate the negative effect of the district heating contract, the maximized expected NPVs for Cases (A) and (B) were compared. These cases were described in general terms in Section 2.2. For this case study, they are further specified according to the following:

(A) District heating can be delivered, but no long-term contract is required.

(B) A 15-year district heating contract is required.

Assuming a uniform probability distribution for the 56 scenarios, the expected NPV of the investments is $7.7 \%$ lower for a district heating contract (Case B) than without a contract constraint (Case A). Note that also low values of relative differences in the $\mathrm{E}[\mathrm{NPV}]$ are generally significant, which is due to the weighting with respect to both scenarios and time. 
Figure 6 illustrates the difference between the optimal solutions for Cases (A) and (B) by comparing their annual net profits in $2020-2025\left(\Delta \mathrm{ANP}_{t, s}\right.$, which is calculated according to Eq. (2)). A zero difference was obtained for all of the scenarios in which lignin was valued as a wood fuel. For the scenarios in which lignin was valued higher after year 2015 (labelled with*), the difference was significant in the time period 2015-2025 (after 2025 a small, almost negligible, difference remains).

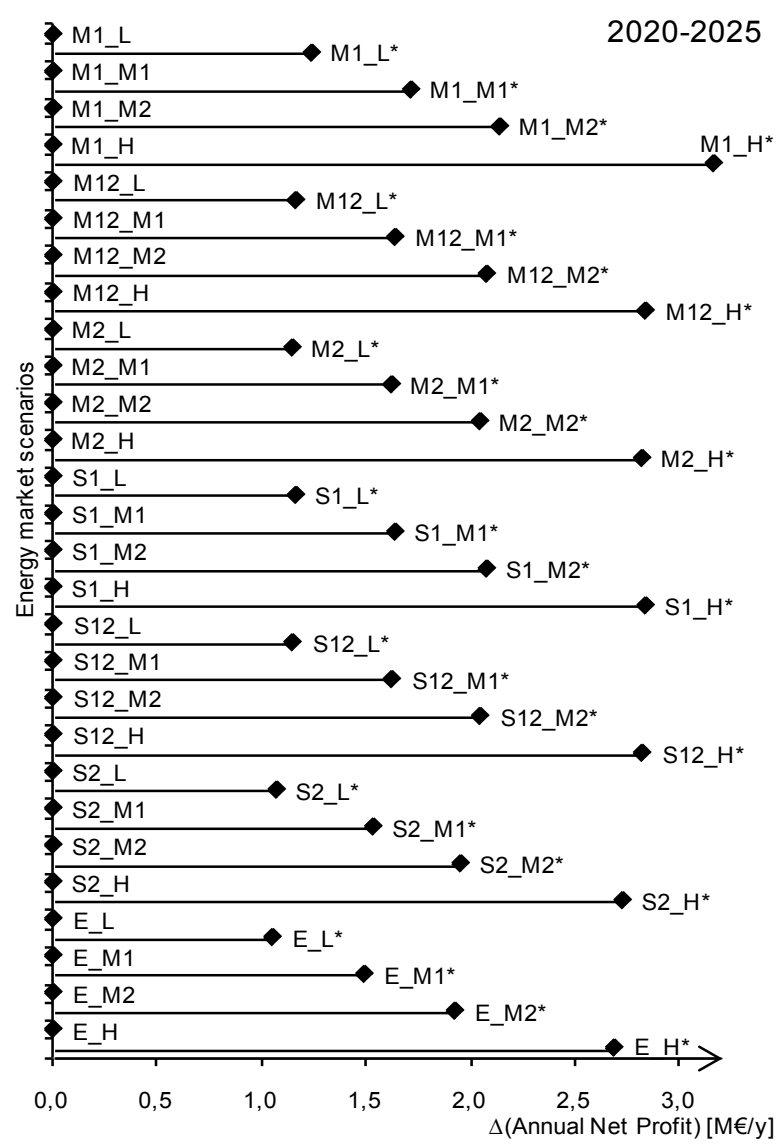

Figure 6. Reduction in the annual net profit due to the district heating contract. The 28 scenarios labelled with * possess the higher lignin price (based on the price of oil instead of wood fuel), otherwise the energy prices are the same as in the original 28 scenarios; see Figure 5. Note that results are shown for only one time period (i.e. 2020-2025).

As illustrated in Figure 6, the reduction in annual net profit due to the district heating contract varies from about one up to over three million Euros per year in 2020-2025 for the EMS with the opportunity for lignin upgrading (the EMS labelled with *). This represents a significant share of the total annual net profit, which varies between 5.2 and $11.5 \mathrm{M} € / \mathrm{y}$ for those scenarios in that time period. The reduction in annual net profit is due to the lower rate of lignin extraction and upgrading when excess heat is used externally for district heating instead of internally for the lignin process. The value of the flexibility obtained by avoiding the district heating contract can thus be evaluated using the results obtained from the MSP-based methodology proposed in [24].

\subsection{Interpretation of case study results with regard to change and flexibility}

The findings of the case study show that under changing conditions it might be optimal to first invest in district heating and electricity production, and later in lignin extraction. This solution could not have been revealed by optimization over constant conditions only. For example, the profitability of the turbine investment depends on its expected operating lifetime, which in turn depends on the expected 
optimal timing of the lignin extraction investment. In order to optimize today's decisions, the change from the current lignin price to a possibly higher price must therefore be considered as well as the possibility to adapt to this change by implementing new investments; the value of the sequence of all investment opportunities over time must therefore be considered.

While lignin extraction and upgrading is promising, it is not a possibility today. District heating is therefore the best option under the current conditions. However, by engaging in a long-term contract for heat deliveries, the future opportunity for lignin upgrading will be lost. Therefore, a decision must be made either to enter into a district heating co-operation today or to wait and choose between the two options later. The optimal decision today depends on the expected NPV of potential future investments in lignin refining, which, in turn depends on which investments have been implemented before the point in time when the lignin refining investment is implemented. The model must therefore capture how the investment profitability depends on both the external conditions, which change over time, and the sequence of investment decisions. The future change in external conditions, combined with opportunities for internal changes through new investments, yields a value to the option of waiting. It also provides a value to flexibility, that is, to options that maintain the ability of the mill to change its operation at a later point in time or to implement new investments.

\section{Discussion}

The example presented in this article demonstrates the necessity of considering the future development of energy prices and of allowing for future investment decisions; so-called recourse decisions [12]. When decisions are made without considering the flexibility required to adjust to future changes there is a risk that their implementation will hinder or drastically increase the cost of a later implementation of new technology, processes or products that would otherwise have become beneficial. If future changes and investment opportunities are considered in the investment optimization model, investments that could lead to an unfavourable future situation cannot be identified as optimal. Therefore, it is essential to model these changes. External and internal changes should be considered in any model for the evaluation of strategic process investments in order to enable the value of flexibility to be properly included in the model.

In Section 4.1, the optimization method employed in this article is briefly discussed. The modelling of the parameters and variables that are most affected by changing conditions is discussed in the subsequent sections. More specifically, Section 4.2 discusses the modelling of scenarios representing a path of change from one state to another while Section 4.3 discusses the economic and technological data required for the step-wise implementation of investments. Finally Section 4.4 discusses the generality and validity of the results.

\subsection{Methodological approach}

The MSP-based optimization approach [24, 25] that has been applied in this project incorporates the modelling of multiple investment opportunities and of EMS that represent a development over time. Consequently, the methodology possesses clear advantages in the context of change and flexibility compared to conventional engineering investment evaluation methods.

To determine which investment decisions yield the best average performance for a given probability distribution, and to ensure that this solution can actually be identified, the MSP approach is fundamental. It is, however, not always necessary to identify the solution with the maximum expected value; the identification of a robust solution may be sufficient. Robustness requirements can be included as constraints on the minimum acceptable NPV in any scenario. 


\subsection{Scenario models}

The importance of modelling how parameter values and decision variables as functions of time suggests that the time steps in the model should be short enough to capture changes in trends in sufficient detail. The current model use time periods of five years of assumed constant conditions. Reducing the length of the time periods may increase the value of waiting because then revenues would not be lost for so many years. The length of the time steps has a greater influence on the optimal solution for the years before a drastic change such as the market introduction of a new technology or a large increase in prices.

Increasing the number of stages in the model leads to a larger EMS model, since each stage typically involves a branching of the scenario tree. This branching not only affects the computational complexity of the scenario model. It also affects the requirement for scenario data that must conform to the scenario tree structure. This can be difficult since scenario data are typically obtained from sources that are not adapted for branched scenario tree models. By performing a deterministic scenario analysis instead of applying the stochastic programming approach for optimization under uncertainty, there is a potential for refining the scenario model without risking intractable solution times. The deterministic approach does not, however, guarantee that an optimal solution will be identified.

\subsection{Decision model and data}

When considering investment opportunities at multiple points in time, it is essential to properly model the cost and technology data for future modifications of an existing process. Examples of such modifications include the capacity expansion of an existing lignin extraction plant and step-wise modifications of the evaporation plant (e.g., to first increase the steam efficiency, and later adapt for the lignin extraction instead of implementing both types of changes at the same time). An example of a change in operating condition is the load reduction of a turbine leading to part-load, off-design efficiencies. Data are needed for the added cost that must be paid today for obtaining the flexibility to enable these future modifications, as well as for the cost for investing in extensions or modifications at future points in time. Investment options that provide this kind of flexibility to the mill might be difficult to identify and to obtain data for. The reason is that investment options and their characteristics are generally based on previous studies that assume investments to be made at one point in time only and that conditions are constant over time. Under such assumptions, flexibility has no explicit value and investment options that are associated with flexibility, but at a higher cost, will not have been included.

The functions connecting the design variables with the dependent characteristics and attributes of the design are typically established by simulations, experimental data, and catalogue selections: the functions are therefore often given only for fixed equipment sizes or for certain process configurations. Cost and performance data for process energy and biorefinery measures are, as a consequence, often available only for a few packaged, alternative combinations. Relevant data might not be available for other combinations of measures or for changes made over time. Therefore, even if technologies and process solutions exist that retain the flexibility of the mill, they might not be included in the model, and can thus not be identified as optimal.

To summarize, data collection is a challenge. To overcome this challenge, it is essential to cooperate well with manufacturers and technology developers in order to develop a mutual understanding of the need to establish this kind of data. In order to include all relevant options in the model it is also necessary to understand what kind of investments would provide flexibility to the pulp mill. 


\subsection{Generality and validity of results}

The case study presented in this article shows only one example of a future emerging technology pathway for a pulp mill - an upgrading process for lignin. Loss of flexibility is represented by the district heating contract and its associated lock-in effect. For the pulp and paper industry, there are of course several other future opportunities as well as potential lock-in effects through which flexibility is lost. It is easy to imagine a mill with a huge amount of capital locked into a new recovery boiler or other capital-intensive process units. But for some mills it is currently better to simply utilize steam savings to reduce their use of bark or oil fuel, while postponing a decision on a more advanced technology pathway until later.

The optimal investment strategy identified for the mill in the case study cannot be assumed to be optimal for a different pulp mill with a different view on the future. However, the findings show that it is important to consider both current and future investment opportunities and changing conditions in the same model when optimizing the decision. The modelling must, nevertheless, be performed for each specific case to determine whether or not current decisions will be influenced by future changes and opportunities. The optimization methodology used in this paper provides a framework for such studies.

Furthermore, the results of the case study indicate that the district heating investment is optimal if district heating can be delivered at the assumed price without a long-term contract. This possibility is, however, not likely in practice. To evaluate the profitability of the district heating investment, a more elaborate modelling is required that takes into consideration the contract requirements and the relation between the contract length and the price.

The optimal decision also depends on the probabilities assumed for the EMS. In the case study, the probability that lignin can be valued as a material/chemical instead of a wood fuel is especially important.

Although the discussions and the case study presented in this article are specific to the pulping industry, the modelling and importance of flexibility and change are most likely to be applicable to other industries and energy system models.

\section{Future research}

A refinement of the scenario model and the implementation of more detailed technology models will result in a more realistic model with regard to flexibility and change. It might also result in a clearer advantage of using the MSP approach instead of deterministic scenario analysis.

However, when increasing the complexity of the associated mathematical optimization models, there is a risk of intractable solution times. More scenarios (including more branches in the scenario tree) will, for example, lead to an exponential increase of the solution time. For example, when moving from a scenario model with 33 nodes to the scenario model used in this paper with 120 nodes, the solution time increased from around one minute to several hours. Future development might therefore be needed in order to improve the computational performance; possible approaches include the decomposition of the optimization models (see e.g. [36]) and special purpose algorithms as well as heuristic algorithms for the identification of close-to-optimal starting solutions. A differentiated time scale with shorter time intervals directly before expected external changes and longer intervals, for example, near the end of the analyzed time span may also be motivated. 
Finally, further research should be emphasized on ensuring that the scenarios represent a plausible development over time. To achieve this, it might be insufficient to construct scenarios based on discrete sets of calculation points at different future years; in addition, the path of change from today's to future conditions must be plausible. This would involve, for example, the modelling of the transformation from one marginal electricity production technology to another.

\section{Conclusions}

This article has shown that the consideration of future investment opportunities and changes in surrounding conditions are vital to the optimal investment plan of a mill and affect the value of today's investments. The case study presented reveals a significant value in the mill being flexible, that is, that the mill is able to respond to changing conditions. In the case study, the loss of flexibility associated with entering a district heating contract was valued at one to three million Euros per year in scenarios in which heat would later be more competitively used for the production of value-added chemicals. The flexibility of retaining this opportunity for biorefinery investment is ensured by avoiding a longterm contract.

The article has illustrated how a systematic optimization methodology can be used to identify strategic investments in pulp mill energy and biorefinery projects. It is, however, essential that the optimization model captures the value of flexibility. With regard to modelling, this is achieved by properly including (1) the development over time of external factors such as energy and product prices and investment costs, and (2) recourse investment decisions that represent later opportunities to respond to changing conditions.

The suggested approach contributes to the decision-making process by enabling not only the optimization of current investment decisions in the face of future opportunities connected to changing conditions, but also the quantitative assessment of pulp mill flexibility.

\section{Acknowledgements}

This project was funded by the Swedish Energy Agency, the Södra Foundation for Research, Development and Education, and the Chalmers Energy Area of Advance.

\section{References}

1. Hämäläinen S, Näyhä A, Pesonen H-L. Forest biorefineries - A business opportunity for the Finnish forest cluster. Journal of Cleaner Production 2011; 19:1884-1891.

2. Chambost V, Eamer R, Stuart P. Systematic methodology for identifying promising forest biorefinery products. Pulp and Paper Canada 2007; 108:30-35.

3. Kemp IC. Pinch Analysis and Process Integration: A User Guide on Process Integration for the Efficient Use of Energy. Butterworth-Heinemann: Oxford, 2007.

4. Smith R. Chemical Process Design and Integration. Wiley: Chichester, 2005.

5. Klemeš J. Sustainability in the Process Industry: Integration and Optimization. McGraw-Hill: New York, 2011.

6. Atkins M, Walmsley M, Morrison A, Neale J. Process integration in pulp and paper mills for energy and water reduction - A review. Appita Journal 2012; 65:170-177.

7. Nemet A, Klemeš JJ, Kravanja Z. Minimisation of a heat exchanger network's cost over its lifetime. Energy 2012; 45:264-276.

8. Ådahl A, Harvey S. Energy efficiency investments in Kraft pulp mills given uncertain climate policy. International Journal of Energy Research 2007; 31:486-505.

9. Tay DH, Ng DK, Tan RR. Robust optimization approach for synthesis of integrated biorefineries with supply and demand uncertainties. Environmental Progress and Sustainable Energy 2013; 32:384-389. 
10. Liu P, Pistikopoulos EN, Li Z. Decomposition based stochastic programming approach for polygeneration energy systems design under uncertainty. Industrial and Engineering Chemistry Research 2010; 49:3295-3305.

11. Dixit AK, Pindyck RS. Investment under Uncertainty. Princeton University Press: Princeton, 1994.

12. Birge JR, Louveaux F. Introduction to Stochastic Programming. Springer: New York, 1997.

13. Ruszczyński A, Shapiro A. Stochastic Programming. In: Lenstra JK, Nemhauser GL, editors. Handbooks in Operations Research and Management Science. Elsevier: Amsterdam, 2003.

14. Kall P, Mayer J. Stochastic Linear Programming: Models, Theory and Computation. Springer: New York, 2005.

15. Blyth W, Bradley R, Bunn D, Clarke C, Wilson T, Yang M. Investment risks under uncertain climate change policy. Energy Policy 2007; 35:5766-5773.

16. Yang M, Blyth W, Bradley R, Bunn D, Clarke C, Wilson T. Evaluating the power investment options with uncertainty in climate policy. Energy Economics 2008; 30:1933-1950.

17. Fuss S, Johansson D, Szolgayová J, Obersteiner M. Investment under market and climate policy uncertainty. Applied Energy 2008; 85:708-721.

18. Fuss S, Szolgayová J. Fuel price and technological uncertainty in a real options model for electricity planning. Applied Energy 2010; 87:2938-2944.

19. Laurikka H. Option value of gasification technology within an emissions trading scheme. Energy Policy 2006; 34:3916-3928.

20. Wickart M, Madlener R. Optimal technology choice and investment timing: A stochastic model of industrial cogeneration vs. heat-only production. Energy Economics 2007; 29:934-952.

21. Diederen $\mathrm{P}$, van Tongeren F, van der Veen H. Returns on investments in energy-saving technologies under energy price uncertainty in Dutch greenhouse horticulture. Environmental and Resource Economics 2003 24:379-394.

22. Chladná Z, Chladný M, Möllersten K, Obersteiner M. Investment under multiple uncertainties: The case of future pulp and paper mills. 2004, IIASA - the International Institute for Applied Systems Analysis: Laxenburg, Austria.

23. Sharma P, Sarker BR, Romagnoli JA. A decision support tool for strategic planning of sustainable biorefineries. Computers and Chemical Engineering 2011; 35:1767-1781.

24. Svensson E, Berntsson T, Strömberg A-B, Patriksson M. An optimization methodology for identifying robust process integration investments under uncertainty. Energy Policy 2009; 37:680-685.

25. Svensson E, Strömberg A-B, Patriksson M. A model for optimization of process integration investments under uncertainty. Energy 2011; 36:2733-2746.

26. Carpaneto E, Chicco G, Mancarella P, Russo A. Cogeneration planning under uncertainty. Part II: Decision theory-based assessment of planning alternatives. Applied Energy 2011; 88:1075-1083.

27. Axelsson E, Harvey S. Scenarios for assessing profitability and carbon balances of energy investments in industry. Pathways to Sustainable European Energy Systems and AGS, the Alliance for Global Sustainability: Göteborg, Sweden, 2010; AGS Pathways report 2010:EU1.

28. Fourer R, Gay DM, Kernighan BW. AMPL: A Modeling Language for Mathematical Programming, $2^{\text {nd }} e d$. Duxbury Press \& Brooks/Cole Publishing Company: Pacific Grove CA, 2003.

29. IBM ILOG. CPLEX: High-Performance Software for Mathematical Programming and Optimization, 12.1. URL: www-01.ibm.com/software/integration/optimization/cplex-optimizer/

30. Persson J, Berntsson T. Influence of short-term variations on energy-saving opportunities in a pulp mill. Journal of Cleaner Production 2010; 18:935-943.

31. Jönsson J, Svensson I-L, Berntsson T, Moshfegh B. Excess heat from Kraft pulp mills: Trade-offs between internal and external use in the case of Sweden - Part 2: Results for future energy market scenarios. Energy Policy 2008; 36:4186-4197.

32. Olsson M, Axelsson E, Berntsson T. Exporting lignin or power from heat-integrated Kraft pulp mills: A techno-economic comparison using model mills. Nordic Pulp and Paper Research Journal 2006; 21:476-484 
33. Olsson M, Berntsson T. Simulations comparing conventional evaporation plants with plants using excess heat. Bioresources 2009; 4:1555-1571.

34. Wallmo H, Wimby M, Larsson A. Increase production in your recovery boiler with LignoBoost Extract valuable lignin for biorefinery production and replacement of fossil fuels. In Proceedings of TAPPI Engineering, Pulping \& Environmental Conference, Memphis, Tennessee, October 1114, 2009; Vol.1: 2568-2593.

35. Svensson E, Berntsson T. Planning future investments in emerging technologies for pulp mills considering different scenarios for their investment cost development. Energy 2011; 36:65086519.

36. Vanderbeck F, Wolsey LA. Reformulation and decomposition of integer programs. In: Jünger M, Liebling TM, Naddef D, Nemhauser GL, Pulleyblank WR, Reinelt G, et al., editors. 50 Years of Integer Programming 1958-2008: From the Early Years to the State-of-the-art. Springer: Heidelberg, 2010; pp. 431-502. 